\title{
Piscine orthoreovirus (PRV) infects Atlantic salmon erythrocytes
}

\author{
Øystein Wessel Finstad ${ }^{1 *}$, Maria Krudtaa Dahle², Tone Hæg Lindholm, Ingvild Berg Nyman ${ }^{1}$, Marie Løvoll ${ }^{3}$, \\ Christian Wallace ${ }^{3}$, Christel Moræus Olsen ${ }^{1}$, Anne K Storset ${ }^{1}$ and Espen Rimstad ${ }^{1}$
}

\begin{abstract}
Piscine orthoreovirus (PRV) belongs to the Reoviridae family and is the only known fish virus related to the Orthoreovirus genus. The virus is the causative agent of heart and skeletal muscle inflammation (HSMI), an emerging disease in farmed Atlantic salmon (Salmo salar L.). PRV is ubiquitous in farmed Atlantic salmon and high loads of PRV in the heart are consistent findings in HSMI. The mechanism by which PRV infection causes disease remains largely unknown. In this study we investigated the presence of PRV in blood and erythrocytes using an experimental cohabitation challenge model. We found that in the early phases of infection, the PRV loads in blood were significantly higher than in any other organ. Most virus was found in the erythrocyte fraction, and in individual fish more than $50 \%$ of erythrocytes were PRV-positive, as determined by flow cytometry. PRV was condensed into large cytoplasmic inclusions resembling viral factories, as demonstrated by immunofluorescence and confocal microscopy. By electron microscopy we showed that these inclusions contained reovirus-like particles. The PRV particles and inclusions also had a striking resemblance to previously reported viral inclusions described as Erythrocytic inclusion body syndrome (EIBS). We conclude that the erythrocyte is a major target cell for PRV infection. These findings provide new information about HSMI pathogenesis, and show that PRV is an important factor of viral erythrocytic inclusions.
\end{abstract}

\section{Introduction}

Piscine orthoreovirus (PRV) is the causative agent of heart and skeletal muscle inflammation (HSMI), an important emerging disease in farmed Atlantic salmon (Salmo salar L.) [1,2]. HSMI is characterized by epi-, endo- and myocarditis, with infiltration of mononuclear CD8 positive cells, as well as myositis in red skeletal muscle [3,4]. The mechanism by which PRV infection causes disease remains largely unknown. PRV has a segmented, double-stranded RNA (dsRNA) genome and belongs to the Reoviridae family [2]. Other fish reoviruses are grouped in the genus Aquareovirus, but phylogenetic analysis indicates that PRV branches off the common root of the genera Orthoreovirus and Aquareovirus, although it clusters more closely with the orthoreoviruses $[5,6]$. PRV has 10 genomic segments, as do the orthoreoviruses, but the overall amino acid identity between the homologous proteins is very low, particularly for the

\footnotetext{
* Correspondence: oyfi@nmbu.no

${ }^{1}$ Department of Food Safety and Infection Biology, Norwegian University of Life Sciences, Oslo, Norway

Full list of author information is available at the end of the article
}

surface-exposed and non-structural proteins. However, several amino acid motifs central to protein function are conserved for orthoreoviruses and PRV [6]. Unlike most orthoreoviruses, but similar to the mammalian orthoreoviruses (MRV), PRV is non-fusogenic [5]. This unique taxonomic placement of a fish virus within the Reoviridae family makes PRV particularly interesting. One genogroup and two sub-groups have been suggested after genomic analysis of PRV, but no specific sequence motifs have been found to be correlated with virulence $[7,8]$. The lack of an in-vitro cultivation system has restricted the progress of the study of PRV.

PRV is ubiquitous in farmed Atlantic salmon. Although high loads of PRV in the heart are a consistent finding in HSMI outbreaks, the virus can be detected at low levels in fish throughout the production cycle $[8,9]$. PRV has also been detected in farmed Atlantic salmon in Canada and Chile, farmed steelhead trout (Oncorhynchus mykiss), wild chum salmon (O. keta) and cutthrout trout (O. clarkii) in Canada [7] and in wild Atlantic salmon and brown trout (Salmo trutta L.) in Norway [10]. MRV infections are also 
ubiquitous in mammals. Although natural infections are generally considered benign, MRV Type 3 Dearing (T3D) has been used to induce myocarditis experimentally in mice [11]. Avian orthoreovirus (ARV) infections in chicken and turkey are associated with several disease conditions [12-14]. In both poultry and aquaculture farming, large numbers of animals are kept confined at high densities. These conditions may be stressful and cause depression of immune responses, while simultaneously facilitating transmission of infectious agents.

HSMI was first described in Norway in 1999 [1]. Since then the number of outbreaks has increased and in 2012 there were 142 registered outbreaks [15]. The disease has also been reported in Scotland [16]. HSMI is mainly observed during the seawater grow-out phase of the fish, with morbidity close to $100 \%$ in affected cages, while cumulative mortality varies from negligible to $20 \%$ [17]. Typical gross pathologic changes in affected fish include signs of circulatory disturbance; pale heart, ascites, yellow liver, swollen spleen and petechiae in perivascular fat.

Diagnosis of HSMI is currently based on typical histopathological findings in heart and red skeletal muscle $[3,4]$. Both the viral load in the heart, as measured by reverse transcription quantitative PCR (RT-qPCR) [4], and the presence of viral proteins in cardiomyocytes, as demonstrated by immunohistochemistry [18], correlate with the development of heart lesions, and indicate that PRV replicates in heart tissue. However, relatively high PRV loads have been detected in both farmed and wild salmon without presence of histopathological changes $[8,10]$.

PRV has been detected in the spleen and head kidney at higher loads than those of the heart [19], and inoculates originating from heart, liver, kidney/spleen and blood plasma from diseased fish have been used to reproduce disease [20]. The pathogenesis of PRV infection in salmon is largely unknown and possible consequences of PRV infection not related to HSMI should be further investigated. Interestingly, when immunohistochemistry was performed on heart sections from experimentally PRV-challenged fish, circulating cells were found to be PRV positive prior to detection of PRV in cardiomyocytes [18]. The PRV-positive blood cells were located in the cardiac lumen and in blood vessels and included both erythrocytes and leukocyte-like cells. Unfortunately, the available material of that experiment was not suitable for further characterization of these cells. The presence of viremia in PRV infection has not been studied.

A previous study of field material from four separate HSMI outbreaks reported several different virus like particles (VLP) by electron microscopy (EM) in erythrocytes, and also in macrophages in the head kidney. However, no known virus species have been linked to these findings [21]. One of these VLPs had similar morphology to those detected in erythrocytes of many species of salmonid fish; collectively called erythrocytic inclusion body syndrome (EIBS) [22-26]. No specific virus has been characterized from the EIBS-inclusions and whether one or several viral species are involved has not been documented.

PRV encodes a homologous protein of the MRV outerfiber protein $(\sigma 1)$ that is present in most members of genus Orthoreovirus and is known to be the cell attachment protein $[5,6]$. MRV bind erythrocytes by the $\sigma 1$ protein [27-30], and amino acid residues central for this binding are partly conserved in the PRV $\sigma 1$ protein $[5,6]$. In contrast to mammalian erythrocytes, piscine red blood cells (RBC) are nucleated and thus have the potential to support viral replication [31].

We hypothesized that there is a cell-associated viremia in PRV infection that is of importance for the pathogenesis. In two consecutive PRV challenge experiments based on cohabitant transfer of virus, we assessed viral loads in blood, plasma and erythrocytes in the different phases of infection.

\section{Materials and methods}

\section{Experimental fish and rearing conditions}

Two consecutive PRV challenge experiments were conducted at VESO Vikan aquatic research facility, Vikan, Norway. Both trials were performed by cohabitation challenge, using unvaccinated, seawater-adapted Atlantic salmon that were confirmed free of known salmon pathogens. The fish were kept in tanks supplied with filtered and UV-radiated $30.5-34.6 \%$ salinity seawater, $12{ }^{\circ} \mathrm{C} \pm$ $0.54{ }^{\circ} \mathrm{C}$ and with a $24 \mathrm{~h}$ light $/ 0 \mathrm{~h}$ dark regime. The fish were acclimatized for 2 weeks prior to challenge, fed according to standard procedures and anesthetized by bath immersion (2-5 min) in benzocaine chloride $(0.5 \mathrm{~g} / 10 \mathrm{~L}$ water) (Apotekproduksjon AS; Oslo, Norway) before handling. Fish were killed using concentrated benzocaine chloride ( $1 \mathrm{~g} / 5 \mathrm{~L}$ water) for $5 \mathrm{~min}$. Control samples from 6 fish were collected before initiation of the experiments. The experiments were approved by the Norwegian Animal Research Authority.

\section{Challenge experiment \# 1}

50 shedders and 50 cohabitants with an initial average weight of $48 \mathrm{~g}$ were used. The inoculum originated from a field outbreak of HSMI as determined by histopathological examination and RT-qPCR that showed high loads of PRV. Four fish from the outbreak, with a mean Ct-value 25.6 for PRV in the heart, were used. The fish were confirmed free of infectious salmon anemia virus (ISAV), salmonid alphavirus (SAV), piscine myocarditis virus $(\mathrm{PMCV})$ and infectious pancreatic necrosis virus (IPNV) by RT-qPCR. The PRV inoculum was prepared by homogenization of the heart, spleen and head kidney. The latter two organs are known to contain higher PRV load than the heart [19]. 
The shedder fish were injected intraperitoneally with $0.1 \mathrm{~mL}$ inoculum, labeled by shortening the outer left maxilla, and placed in a tank containing 50 naïve fish (cohabitants). The samples from challenge \# 1 were collected from the cohabitant group; sampling six fish every second week starting at 6 weeks post challenge (wpc) and ending at $14 \mathrm{wpc}$. In addition, 3 cohabitant fish were sampled at $4 \mathrm{wpc}$ to test for transmission of PRV. At each sampling, peripheral blood from the caudal vein was collected into heparinized vacutainers, and tissue from heart, skeletal muscle, spleen and head kidney were sampled in RNAlater (Life Technologies, Carlsbad, CA, USA) and used for RT-qPCR analysis. Parallel samples from the same organs were harvested in $10 \%$ phosphatebuffer formalin, embedded in paraffin, and used for histologic analysis.

At 9 wpc, blood from 15 cohabitant fish was sampled, pooled and centrifuged. After removing the plasma, the blood pellet was diluted 1:4 in phosphate-buffered saline (PBS) and stored at $-80{ }^{\circ} \mathrm{C}$. The Ct-value of the diluted blood pellet was confirmed to contain high loads of PRV by RT-qPCR (Ct-value 19.9) and was used as challenge material in Challenge Experiment \# 2. It was also confirmed free of other important viral pathogens of salmon, including ISAV, IPNV, SAV and PMCV.

\section{Challenge experiment \# 2}

60 shedders and 60 cohabitants with an initial average weight of $90 \mathrm{~g}$ were used. The blood pellet prepared in Challenge Experiment \# 1 was thawed, diluted 1:3 in PBS, and used as challenge material. Inoculation and labeling of the shedders were performed as in Challenge Experiment \# 1. The samples from challenge \# 2 were collected from the cohabitant group; six fish were sampled weekly from 2 wpc until 8 wpc. Blood, heart and spleen tissues were sampled as described in Challenge Experiment \# 1. Samples for RT-qPCR were taken from heparinized blood as well as the plasma fraction collected after centrifugation at $1000 \times g$ for $5 \mathrm{~min}$. The remaining blood was used for isolation of $\mathrm{RBC}$, which were subsequently analyzed by RT-qPCR, flow cytometry, fluorescence and confocal microscopy, and transmission electron microscopy (TEM).

\section{Isolation of red blood cells}

$\mathrm{RBC}$ were isolated from the heparinized blood collected from the cohabitant group in Challenge Experiment \# 2 by using a previously described Percoll gradient with minor modifications [32]. In short, blood was diluted 1:10 in distilled PBS (dPBS) and a discontinuous Percoll gradient (GE Healthcare, Uppsala, Sweden) was prepared using $1.07 \mathrm{~g} / \mathrm{mL}$ (49\%) and $1.05 \mathrm{~g} / \mathrm{mL}$ (34\%). The diluted blood was layered onto the gradient and centrifuged at $2000 \times g$ for $20 \mathrm{~min}$ at $4{ }^{\circ} \mathrm{C}$. The $\mathrm{RBC}$ were collected from the bottom of the gradient; however a variable amount of erythrocytes was present at the 34\%-49\% interface. In order to collect the remaining erythrocytes, the interface was re-layered onto a fresh $34 \%-49 \%$ gradient and centrifuged at $500 \times g$ for $10 \mathrm{~min}$ at $4{ }^{\circ} \mathrm{C}$. The $\mathrm{RBC}$ from the bottom of the gradient were collected, pooled with the erythrocytes from the first gradient, and washed twice in PBS. The cells were counted using Countess (Invitrogen, Eugene, Oregon, USA) and resuspended in PBS to a final concentration of $5 \times 10^{6}$ cells $/ \mathrm{mL}$. Smears of the isolated RBC stained with Diff-Quik (Dade Behring, Newark, USA) confirmed that the isolated cells were erythrocytes.

\section{RNA isolation}

Total RNA was isolated from $25 \mathrm{mg}$ of tissue stored in RNAlater by homogenization in QIAzol Lysis Reagent (Qiagen, Hilden, Germany) using $5 \mathrm{~mm}$ steel beads and TissueLyser II (Qiagen) for $2 \times 5 \mathrm{~min}$ at $25 \mathrm{~Hz}$. After addition of chloroform and centrifugation, the aqueous phase was collected and mixed with one volume of $70 \%$ ethanol before continuing with the RNeasy Mini spin column (Qiagen) as described by the manufacturer. The homogenization and RNA extraction method described above was also used for isolation of total RNA from the heparinized blood samples and isolated RBC using $10 \mu \mathrm{L}$ blood and $1 \times 10^{7} \mathrm{RBC}$, respectively. For the plasma samples, a combination of Trizol LS (Invitrogen) and RNeasy Mini spin column was used. Briefly, $50 \mu \mathrm{L}$ plasma was mixed and incubated with Trizol LS before adding chloroform, separating the phases by centrifugation, and then proceeding with the RNeasy Mini spin column as recommended by the manufacturer. The RNA isolated from $50 \mu \mathrm{L}$ plasma was eluted in $50 \mu \mathrm{L}$ RNase-free water. RNA was quantified using a NanoDrop ND-1000 spectrophotometer (Thermo Fisher Scientific, Wilmington, DE, USA).

\section{RT-qPCR}

The Qiagen OneStep kit (Qiagen) was used for RT-qPCR. A standard input of $100 \mathrm{ng}(5 \mathrm{uL}$ of $20 \mathrm{ng} / \mathrm{uL})$ from the isolated total RNA was used in each reaction in order to compare the amount of PRV in tissue, blood and RBC samples. From the cell free plasma samples $5 \mu \mathrm{L}$ purified RNA solution, equivalent to $5 \mu \mathrm{L}$ plasma, was used. The template RNA were denaturated at $95{ }^{\circ} \mathrm{C}$ for 5 min prior to RT-qPCR that was performed using the following conditions: $400 \mathrm{nM}$ primer, $300 \mathrm{nM}$ probe, $400 \mathrm{nM}$ dNTPs, $1.26 \mathrm{mM} \mathrm{MgCl}_{2}, 1: 100$ RNase Out (Invitrogen) and $1 \times \mathrm{ROX}$ reference dye with the following cycle parameters: $30 \mathrm{~min}$ at $50{ }^{\circ} \mathrm{C}, 15 \mathrm{~min}$ at $94{ }^{\circ} \mathrm{C}$, 40 cycles of $94{ }^{\circ} \mathrm{C} / 15 \mathrm{~s}, 54{ }^{\circ} \mathrm{C} / 30 \mathrm{~s}$ and $72{ }^{\circ} \mathrm{C} / 15 \mathrm{~s}$ in a Mx3005P (Stratagene, La Jolla, CA, USA). The samples were run in duplicate, and a sample was defined as 
positive if both parallel samples had a $\mathrm{Ct}<35$. The primers and probe used targeted PRV gene segment S1: S1Fwd TGCGTCCTGCGTATGGCACC; S1Rev GGCTGGCAT GCCCGAATAGCA; S1probe (FAM) ATCACAACGCC TACCT MGBNFQ.

\section{Histopathology}

Slides from the formalin fixed and paraffin embedded heart material collected from Challenge Experiments \# 1 and 2 was stained with hematoxylin-eosin (HE) and evaluated by histopathological examination using conventional light microscopy.

\section{Flow cytometry}

$\mathrm{RBC}$ isolated from the cohabitants in Challenge Experiment \# 2 were stained using a polyclonal antibody raised in rabbits against putative PRV outer capsid protein ơ 1 (Anti-o1, \#K275) [18], running parallel samples for surface and intracellular labeling. All incubations were performed on ice and the corresponding zero serum (Anti- $\sigma 1$ Zero \#K275) (18) was used as negative control serum. Briefly, cells were plated into 96-well plates at densities of $0.5 \times 10^{6}$ cells per well and washed in staining buffer (PBS $+1 \%$ BSA $+0.05 \%$ azide). Cells were surface stained with Anti- $\sigma 1$ (1:10000) for $30 \mathrm{~min}$ and secondary Alexa Fluor 488 conjugated anti-rabbit IgG (Molecular Probes, Eugene, Oregon, USA) (2 $\mathrm{mg} / \mathrm{mL}$ diluted 1:800) for $30 \mathrm{~min}$ using staining buffer in all washes and dilutions. Prior to intracellular staining the cells were fixed and permeabilized by incubation in Cytofix/Cytoperm (Becton Dickinson, San Diego, CA, USA) for $15 \mathrm{~min}$ on ice, and the same primary and secondary incubations described above but using Perm/wash (Becton Dickinson) in the dilutions and washing steps. The cells were read on a Gallios Flow Cytometer (Beckman Coulter, Miami, FL, USA) counting 50000 cells per sample, and the data were analyzed using the Kaluza software (Becton Dickinson). Due to slight variation in the background staining, the flow charts were gated individually, discriminating between negative and positive peaks.

\section{Immunofluorescence microscopy and confocal microscopy}

Samples of the intracellularly stained RBC were prepared for immunofluorescence and confocal microscopy. The nuclei were stained with propidium iodide $(0.5 \mu \mathrm{g} / \mathrm{mL}$, Molecular Probes) and the cells were mounted to glass slides using Fluoroshield (Sigma-Aldrich, St. Louis, USA) and cover slips. Non-saturated images were captured by a Plan-Apochromat 63/1.4 oil objective in a laser scanning confocal microscope (Zeiss Axiovert $200 \mathrm{M}$ fluorescence inverted microscope, equipped with a LSM 510 laser confocal unit $488 \mathrm{~nm}$ argon laser and $546 \mathrm{~nm}$ helium/neon laser Z). In addition, samples were stained with propidium iodide as described above and the cell suspension was transferred to Countess chamber slides (Invitrogen). Photographs were taken by an inverted fluorescence microscope (Olympus IX81), at $20 \times$ and $40 \times$ magnification.

\section{Pinacyanol chloride staining of cytoplasmic inclusions}

Blood and isolated RBC from cohabitant fish of challenge \# 2 were collected 8 wpc and used to prepare blood smears for staining with pinacyanol chloride. The staining was performed as previously described by Leek et al. [26]. Briefly; slides were fixed in methanol for $5 \mathrm{~min}$, and subsequently stained in pinacyanol chloride (prepared by mixing $0.25 \mathrm{~g}$ pinacyanol chloride (Santa Cruz Biotechnology) in $35 \mathrm{~mL}$ ethanol and $15 \mathrm{~mL}$ distilled water) for $1 \mathrm{~min}$ and washed with tap water for 5 min. Dry slides were mounted (Aquamount) before microscopy. Pictures were captured at $40 \times$ magnification.

\section{Transmission electron microscopy (TEM)}

$\mathrm{RBC}$ isolated from infected fish were fixed overnight at $4{ }^{\circ} \mathrm{C}$ in PBS with $1.25 \%$ glutaraldehyde and $2 \%$ paraformaldehyde, washed twice in PBS, and three times in cacodylate buffer $(0.1 \mathrm{M}, \mathrm{pH}$ 6.8) The cells were postfixed with $1 \% \mathrm{OsO}_{4}$ for $1 \mathrm{~h}$ at $4{ }^{\circ} \mathrm{C}$ and washed with cacodylate buffer. The cells were then dehydrated through an ethanol series (70, 90, 96 and 100\%) and embedded in LR-White resin. Thin sections were cut on an ultra microtome (LEICA EM UC 6). The sections were stained with $4 \%$ aqueous uranyl acetate and $1 \% \mathrm{KMNO}_{4}$ for $10 \mathrm{~min}$, then washed intensively in freshly distilled water. The sections were examined in a FEI MORGAGNI 268, and photographs were recorded using a VELETA camera.

\section{Data analysis}

The Ct-values for PRV in blood were compared with those of the heart, skeletal muscle, spleen and head kidney from the same individual by paired analysis in both Challenge Experiment \# 1 and \# 2, excluding noninfected individuals. The differences were analysed statistically using Wilcoxon matched pairs signed rank test due to the sample size $(n=6)$. At $6 \mathrm{wpc}$ and $12 \mathrm{wpc}$ in Challenge Experiment \# 1 only four and five out of the six sampled fish could be compared respectively. The non-parametric Mann-Whitney test was used when analysing the difference between $\mathrm{Ct}$-values for PRV in blood obtained in Challenge Experiment \# 1 and \# 2 . The side scatter data of the negative and high PRV positive erythrocytes obtained by flow cytometry was analyzed for each time-point by Wilcoxon matched pairs signed rank test due to the non-normality of the data. All statistical analysis described were performed with GraphPad Prism (GraphPad Software inc., USA) and $p$-values of $p \leq 0.05$ were considered as significant. 


\section{Results}

\section{High PRV load in blood during infection}

The RT-qPCR results from Experimental Challenge \# 1 revealed a high PRV load in heparinized whole blood samples from the cohabitants. PRV was first detected in blood of cohabitant fish at 6 wpc, and the amount of virus peaked at 8 wpc with a mean Ct-value of $18.6( \pm 0.7)$. High viral loads were present in blood until the end of the study at 14 wpc. The mean Ct-values in blood and those in heart and skeletal muscle, which are the main organs for histopathological changes during HSMI [3], are shown in Figure 1A. The relative amounts of virus in blood were significantly higher than those in both heart and skeletal muscle samples at 8, 10 and $14 \mathrm{wpc}(p<0.05)$ (Figure 1B). Compared to the spleen and head kidney, which are the visceral organs known to contain most virus during an infection [19], the amount of PRV in blood exceeded that of spleen and head kidney in the early phases (6 wpc). The relative PRV load in spleen and head kidney increased compared with that in blood during the infection and in the later phase of infection $(14 \mathrm{wpc})$, there were significantly higher viral loads in the spleen $(p<0.05)$. All Ctvalues from Experimental Challenge \# 1 are listed in additional file (Additional file 1). Histopathological changes in the heart consistent with an HSMI diagnosis were first observed at $10 \mathrm{wpc}$ in three out of six fish (data not shown).

\section{Blood cell pellet is a highly effective challenge material}

A blood cell pellet prepared from Experimental Challenge \# 1 was used as inoculum in shedder fish in Experimental Challenge \# 2, and, again, high viral loads were detected in blood in the cohabitants (Figure 2A). PRV was first detected in three out of six fish at 4 wpc (i.e., two weeks earlier than in Experimental Challenge \# 1), and at 5 wpc all cohabitant fish sampled were PRV-positive by RT-qPCR.
The maximum viral load in blood occurred two weeks earlier than in Experimental Challenge \# 1, and plateaued at $6 \mathrm{wpc}$, with a mean Ct-value of $16.5( \pm 0.7)$. This is significantly higher than the viral loads at the same time point in Experimental Challenge \# $1(p<0.05)$. The spleen was used as a reference organ for viral load during PRV infection. PRV loads of blood were significantly higher compared with that of the spleen in the early phases of the infection $(5-7 \mathrm{wpc})(p<0.05)$ and shifting to significantly lower levels at 8 wpc $(p<0.05)$ (Figure 2B). Histopathological changes in heart and skeletal muscle consistent with an HSMI diagnosis were first observed at $7 \mathrm{wpc}$ in Experimental Challenge \# 2 in four out of six fish (Figure 2C). At $8 \mathrm{wpc}$, heart lesions were detected in all fish sampled, showing massive epicarditis and infiltration of lymphocytic cells in the compact and spongy myocardium layer of the ventricle.

\section{High PRV loads in RBC}

PRV was first detected in RBC from cohabitants in Experimental Challenge \# 2 by RT-qPCR at 4 wpc and plateaued at about 6 to $7 \mathrm{wpc}(18.5 \pm 2.9$ and $17.5 \pm 2.9$ respectively), thus following the same pattern observed in blood (Figure 2A). Plasma also contained a substantial amount of virus, partly explaining the slightly higher level of virus in whole blood compared with RBC. All Ct-values from Experimental Challenge \# 2 are listed in additional file (Additional file 2).

\section{High numbers of PRV-positive RBC detected by flow cytometry}

The isolated RBC from Experimental Challenge \# 2 were gated according to size and granularity to include only intact cells (Figure 3A). Samples from $0 \mathrm{wpc}$ were used as negative controls, providing the background fluorescence

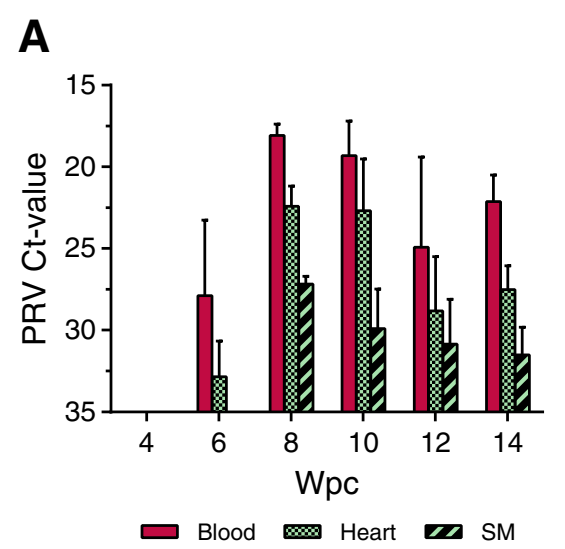

B

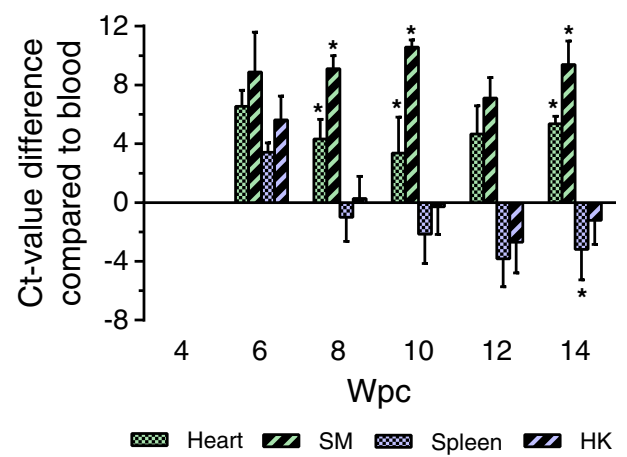

Figure 1 High PRV load in blood detected in Experimental Challenge \# 1. (A) Detection of PRV by RT-qPCR in Challenge Experiment \# 1 presented by mean (and SD) Ct-values in blood, heart and skeletal muscle (SM) $(n=6)$. (B) Paired analysis of the PRV Ct-value detected in blood compared with samples from heart, skeletal muscle (SM), spleen, head kidney (HK) of the same fish. The results are presented as the mean Ct-value difference at each time point. Data were analyzed using Wilcoxon matched pairs signed rank test. ${ }^{*} p<0.05$. 


\section{A}

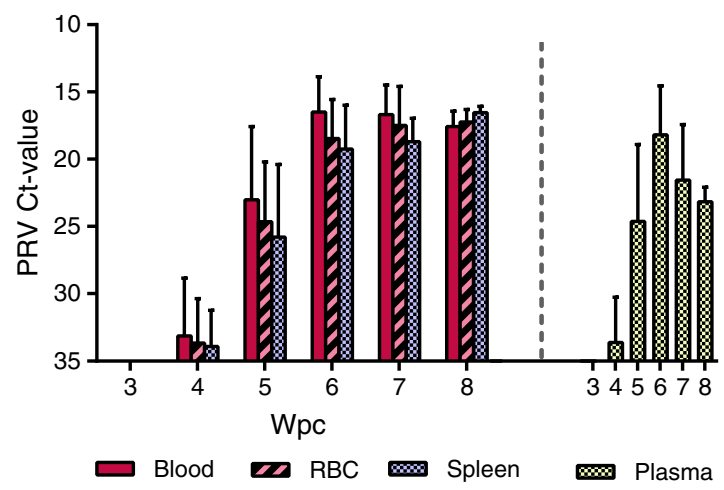

B

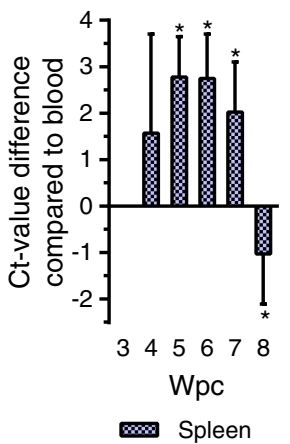

C

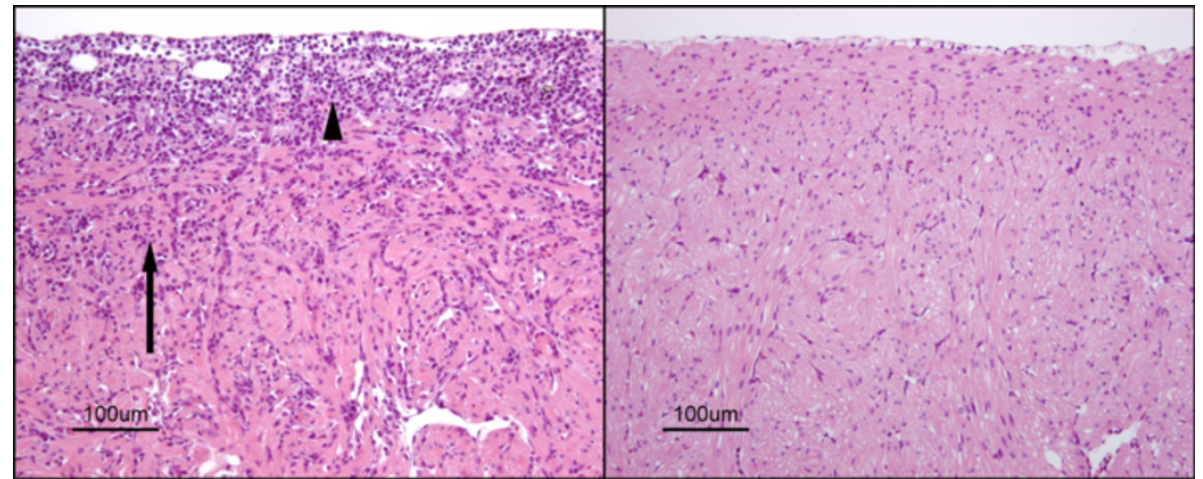

Figure 2 High PRV load in RBC detected in Experimental Challenge \# 2. (A) Detection of PRV by RT-qPCR in Challenge Experiment \# 2 presented by mean (and SD) Ct-values for blood, RBC and spleen. The PCR results from the plasma are shown separately on the right, as the RNA input from the cell free plasma is not directly comparable to the other sample material analyzed. (B) Paired analysis of the PRV Ct-value detected in blood compared with spleen from the same fish, presented as mean Ct-value difference at each time point. Data were analyzed using Wilcoxon matched pairs signed rank test. ${ }^{*} p<0.05$. (C) Histopathological changes in the ventricle of the heart at 7 weeks post challenge (wpc) (left) consistent with HSMl, including epicarditis (arrowhead) and inflammation of the compactum myocardium layer (arrow). For comparison a ventricle without inflammatory changes (sampled at $0 \mathrm{wpc}$ ), is shown to the right.

signal from PRV-negative samples (Figure 3B). A PRV-positive erythrocyte population was first observed in two out of six individuals (F55, F56) at $5 \mathrm{wpc}$, as seen by a peak in fluorescence signal for both intracellular and surface staining. The majority of virus protein was detected intracellularly and a large, distinct population of PRV-positive RBC (up to 43\% of cells PRV-positive in F56) could be observed (Figure 3C). As shown by RT-qPCR of $\mathrm{RBC}$, the individual fish that were PRV-positive also contained distinctly higher viral loads compared with the rest of the group (Table 1). PRV was also detected on the surfaces of a small number of RBC of the same individuals. The surface staining data from Experimental Challenge \# 2 is shown in additional file (Additional file 3).

At 7 wpc, PRV-positive erythrocytes from Experimental Challenge \# 2 were observed in four out of five individual fish and a considerable proportion of isolated RBC (25 - 51\%) were PRV-positive (Figure 3C). The majority of the virus was found intracellularly. In contrast with the 5 wpc samples, the PRV-positive cells at 7 wpc could be divided into two separate populations, showing low PRV-positive and high PRV-positive staining. The low PRV-positive population was comparable in intensity to the single PRV population detected at $5 \mathrm{wpc}$, indicating a development of cells containing high PRV levels over time (Figure 3C). At $8 \mathrm{wpc}$, high numbers of PRVpositive RBC were detected by intracellular staining in all six individuals. However, at 8 WPC the cells no longer clearly formed two populations of low and high PRV-positive staining.

The results from the flow cytometry analysis correlated with the RT-qPCR results, as individual fish with Ct-values below 20 were consistently detected as positive by flow cytometry (Figure 3C, Table 1). Samples with Ct-values above 20 appeared to be below the sensitivity threshold of the flow cytometry analysis, exemplified by F74 at 7 wpc (Figure 3C). At 4 wpc all the RBC samples had Ct-values above 20, producing only a background 
A

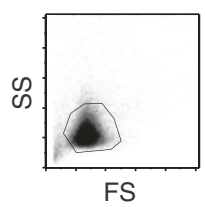

C

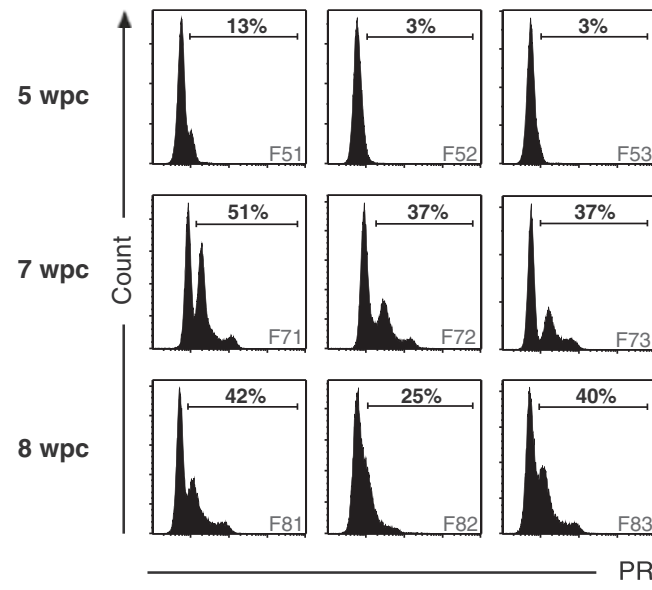

PRV $\sigma$
B

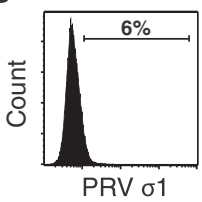

D

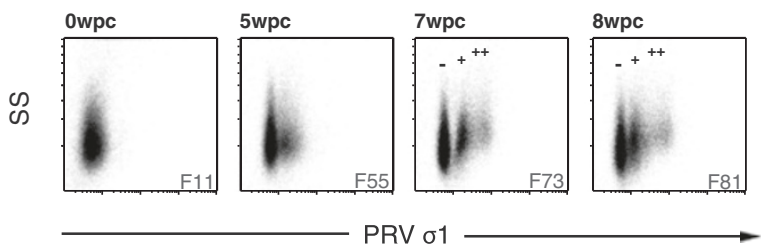

Figure 3 PRV-positive RBC detected by flow cytometry. Detection of PRV protein in isolated RBC from Experimental Challenge \# 2 by flow cytometry. (A) Density plot showing the gating strategy for intracellular staining. FS, forward scatter; SS, side scatter. (B) Negative control from 0 weeks post challenge (wpc) for intracellular staining, representing the background fluorescence. (C) Flow cytometry result from the intracellular staining at 5, 7 and 8 wpc. 50000 cells were counted for each sample. Individual F75 was excluded due to technical difficulties. (D) Plots of side scatter (SS) and fluorescence intensity (PRV ơ1) from 0, 5, 7 and 8 wpc. PRV negative $(-)$, low positive (+) and high positive (++) population are indicated at 7 and $8 \mathrm{wpc}$.

Table 1 Ct-values of PRV in RBC from Challenge \# 2

\begin{tabular}{ccccccc}
\hline \multicolumn{7}{c}{ PRV Ct-value (RBC) } \\
\hline 0 wpc & $\mathbf{3}$ wpc & $\mathbf{4}$ wpc & $\mathbf{5}$ wpc & $\mathbf{6}$ wpc & $\mathbf{7}$ wpc & $\mathbf{8}$ wpc \\
\hline F01-F06 & F31-F36 & $F 41-F 46$ & $F 51-F 56$ & $F 61-F 66$ & $F 71-F 76$ & $F 81-F 86$ \\
No Ct & No Ct & No Ct & 28.2 & 17.8 & 16.8 & 15.7 \\
No Ct & No Ct & No Ct & 25.1 & 23.9 & 15.5 & 17.5 \\
No Ct & No Ct & No Ct & 29.1 & 16.8 & 15.9 & 16.5 \\
No Ct & No Ct & No Ct & 27.1 & 16.1 & 23.2 & 18.1 \\
No Ct & No Ct & No Ct & 19.0 & 16.8 & 17.5 & 17.9 \\
No Ct & No Ct & 26.9 & 19.3 & 19.5 & 17.9 & 17.8
\end{tabular}

RT-qPCR Ct-values of PRV in RBC from individual fish of Experimental Challenge \# 2 at 0 and $3-8$ weeks post challenge (wpc). Unique identifiers for the six individual fish sampled at each time point are included (Ex. F01-F06 at 0 wpc) counting from the top down of each column. signal by flow cytometry; at 8 wpc, all samples had Ctvalues below 20 and were positive by flow cytometry (Figure 3C).

Throughout the study PRV-positive cells with high fluorescence intensity tended to show an increased side scatter in flow cytometry (Figure 3D). The negative population and high PRV-positive populations were individually gated in each fish, and their mean side scatter was compared using Wilcoxon rank-sum test. The high PRVpositive populations at $7 \mathrm{wpc}$ and $8 \mathrm{wpc}$ had significantly more cells demonstrating higher side scatter properties compared with the negative population $(p<0.05)$ indicating that highly PRV-positive RBC are more granular.

\section{Viral cytoplasmic inclusions detected in RBC}

PRV-positive erythrocytes were identified by immunofluorescence microscopy by granular staining in the cytoplasm (Figure 4A). The staining was observed as inclusions that 
varied in size and number from a few large inclusions to multiple smaller inclusions, or diffuse granular staining throughout the cytoplasm (Figure 4B). The morphology of the positive $\mathrm{RBC}$ varied from typical mature erythrocytes, with an ellipsoidal shape, to more circular cells. The PRVpositive staining was confirmed to be cytoplasmic by confocal microscopy, and the viral inclusions were primarily detected in the perinuculear region, but also found scattered in the cytoplasm (Figure $4 \mathrm{C}$ ). Small inclusions were also observed in the nucleus in some cells (Figure $4 \mathrm{C}$, ii-iv). Cytoplasmic inclusions were also observed in some RBC by phase contrast microscopy, and these inclusions co-localized with the immunofluorescent staining of PRV (Figure 4D).

\section{Viral inclusions detected by pinacyanol staining}

Cytoplasmatic inclusions were detected using pinacyanol chloride staining method observed as single or several small, or single big inclusion(s) were observed (Figure 5). Slides stained with pinacyanol chloride were best observed without mounting media as the stain tended to leak into the mounting media.

\section{Reovirus-like particles observed by TEM}

The TEM analysis of RBC from infected fish revealed cytoplasmic inclusions (Figure 6A), which contained reovirus-like particles (Figure 6B). The inclusions varied in content and size from approximately 100-1000 nm. Some of the inclusions consisted only of lamellar structures up to $500 \mathrm{~nm}$ (Figure 6C). The larger inclusions contained both these lamellar structures and reovirus-like particles (Figure 6D), whereas the biggest inclusions contained only viral particles (Figure 6E). These differences may represent the various stages of the viral replication cycle. Many of inclusions were enclosed within a membrane-like structure that seemed to be partly or fully intact (Figures 6B-E). The viral particles were naked with an outer diameter of approximately $72 \mathrm{~nm}$ (Figures 6B and E). A more electron dense core, with a diameter of about $30 \mathrm{~nm}$, was visible in many of the particles. These features are consistent with descriptions of other members of the reovirus family.

\section{Discussion}

In this study we demonstrate that $\mathrm{RBC}$ are major target cells for PRV. RBC contained high levels of PRV protein and RNA as shown by flow cytometry and RT-qPCR respectively. PRV protein was located to cytoplasmic inclusions resembling viral factories as observed by immunofluorescence and confocal microscopy. Finally, these inclusions were shown by TEM to contain reovirus-like
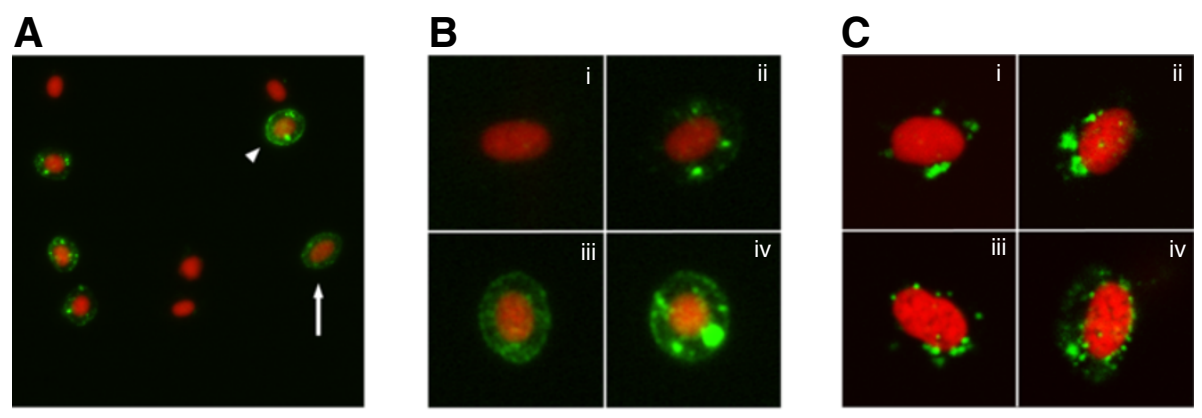

D

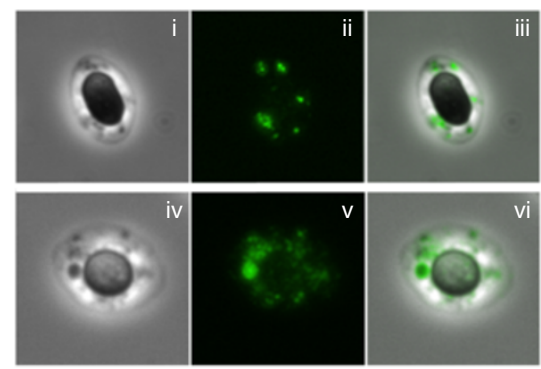

Figure 4 Immunofluorescence and confocal microscopy of PRV positive RBC. Fluorescent labeling of the PRV ơl-protein in erythrocytes (green). Cell nucleus stained with propidium iodide (red). (A) Positive RBC detected by immunofluorescence (IF) microscopy. Labeled cells varied in morphology from elongated mature RBC (arrow) to more spherical cells resembling immature erythrocytes (arrowhead). (B) IF microscopy of a negative cell (i) and different staining pattern in the cytoplasm including a few smaller inclusions (ii), scattered granular staining (iii), and large cytoplasmic inclusions (iv). (C) Confocal microscopy images showing viral inclusions in the perinuclear region (i-iii) and a more scattered staining pattern (iv). (D) Cytoplasmic inclusion detected by phase contrast (i, iv) and IF (ii, v) microscopy, and co-localized by image overlay (iii, vi). 


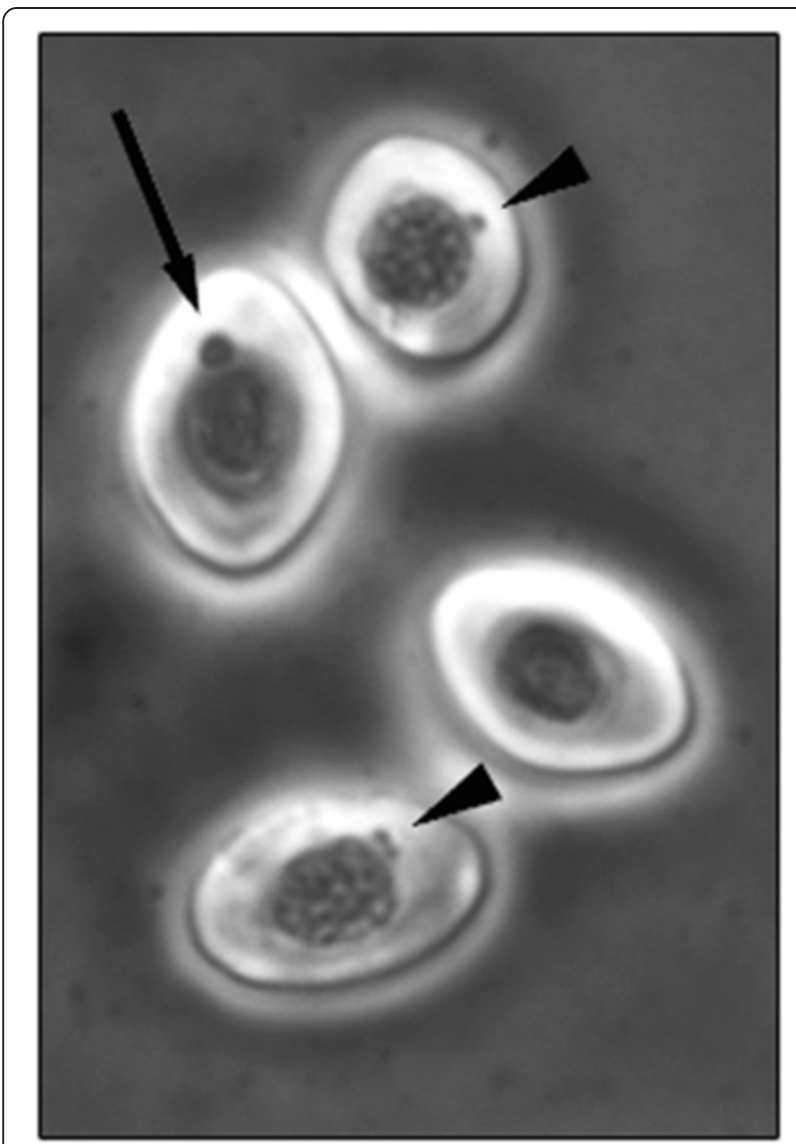

Figure 5 Pinacyanol chloride staining of RBC. Cytoplasmic inclusions detected in blood smears from PRV positive fish. Both small (arrowhead) and large inclusions (arrow) were observed in cytosol of RBC. Picture were taken at $40 \times$ magnification.

particles. All together, these observations show PRV infection of Atlantic salmon erythrocytes.

In Experimental Challenge \# 1, we found that a major part of the PRV load is present in blood and the PRV levels in blood exceeded those of the organs displaying pathological changes i.e. heart and skeletal muscle. Based on these initial results, a blood cell pellet was used as inoculum in Experimental Challenge \# 2, and this generated high loads of PRV in cohabitant fish. Currently there are no in vitro assays to quantify infectious units of PRV. However, the successful transmission of PRV to cohabitant fish after injection of blood cell pellet to the shedder fish, confirmed the presence of infectious virus in blood. The results from RT-qPCR and flow cytometry analysis of Challenge Experimental Challenge \# 2 revealed that the blood borne PRV were mainly present in the erythrocyte fraction.

Immunofluorescence and confocal microscopy demonstrated that PRV condensed into globular structures, localized to the cytoplasm of infected RBC. Furthermore, the flow cytometry analysis showed that highly PRV- positive RBC had a significantly higher side scatter, and were thus more granular than the PRV-negative RBC in an infected individual. Orthoreovirus-infected cells are associated with phase-dense inclusions in the cytoplasm, known as viral factories [33,34]. These viral factories contain large amounts of viral proteins [34,35], dsRNA [36], and partially or fully assembled particles [34], and are considered to be the location where viral RNA replication and packaging, and assembly of progeny particles occurs [33,37]. The inclusions observed in this study appear very similar to those described for orthoreoviruses; more specifically, they resemble the globular viral factories seen in MRV type 3 prototype strain Dearing (T3D) infected cells, rather than the microtubule-associated filamentous factories of the type 1 prototype strain Lang (T1L) $[38,39]$. The capacity of MRV to form viral factories facilitates successful viral replication [40-44].

The viral inclusions observed in this study were found by TEM to contain large amounts of reovirus-like particles. The features were similar to those reported for the Reoviridae family, with naked virions with an outer diameter of $72 \mathrm{~nm}$ and an electron-dense center of $30 \mathrm{~nm}$. Negative- stain EM of MRV has indicated a virion diameter of $73 \mathrm{~nm}$, while the infectious subviral particles (ISVPs) and cores, that are two types of partially uncoated MRV particles, were 64 and $51 \mathrm{~nm}$ respectively [45]. The diameters obtained by cryo-EM, in which reduce shrinking artifacts, are 85,80 and $60 \mathrm{~nm}$ for virions, ISVPs and cores respectively $[46,47]$. If the electron-dense center reported in this study represents the reovirus core, then it is smaller than for MRV. It could, however, represent the centrally condensed RNA genome $[35,48,49]$. Further studies including gradient ultracentrifugation and negative staining are needed to obtain a more detailed description of the PRV particle.

The inclusions varied in size from 100 to $1000 \mathrm{~nm}$ and were often located in the perinuclear region. The content of the inclusions differed, with some filled with reovirus-like particles while others contained a mixture of virus particles and a more homogenous material with lamellar structures. The nature of these lamellar structures was not determined. MRV inclusions have been shown to contain both microtubules and intermediate filaments [35,50,51], and Sharpe et al. have described the intermediate filament, vimentin, being rearranged in reovirus-infected CV-1 cells, both surrounding and incorporating into the viral inclusions [52]. Most of the inclusions detected in our study were encapsulated by a membrane-like structure, whereas in others the membrane seemed to be broken, incomplete, or absent. MRV inclusions are not associated with membranes or other cellular organelles $[34,53,54]$. Whether the membranelike structures observed in our study were lipids or proteinaceous in nature was not determined. 


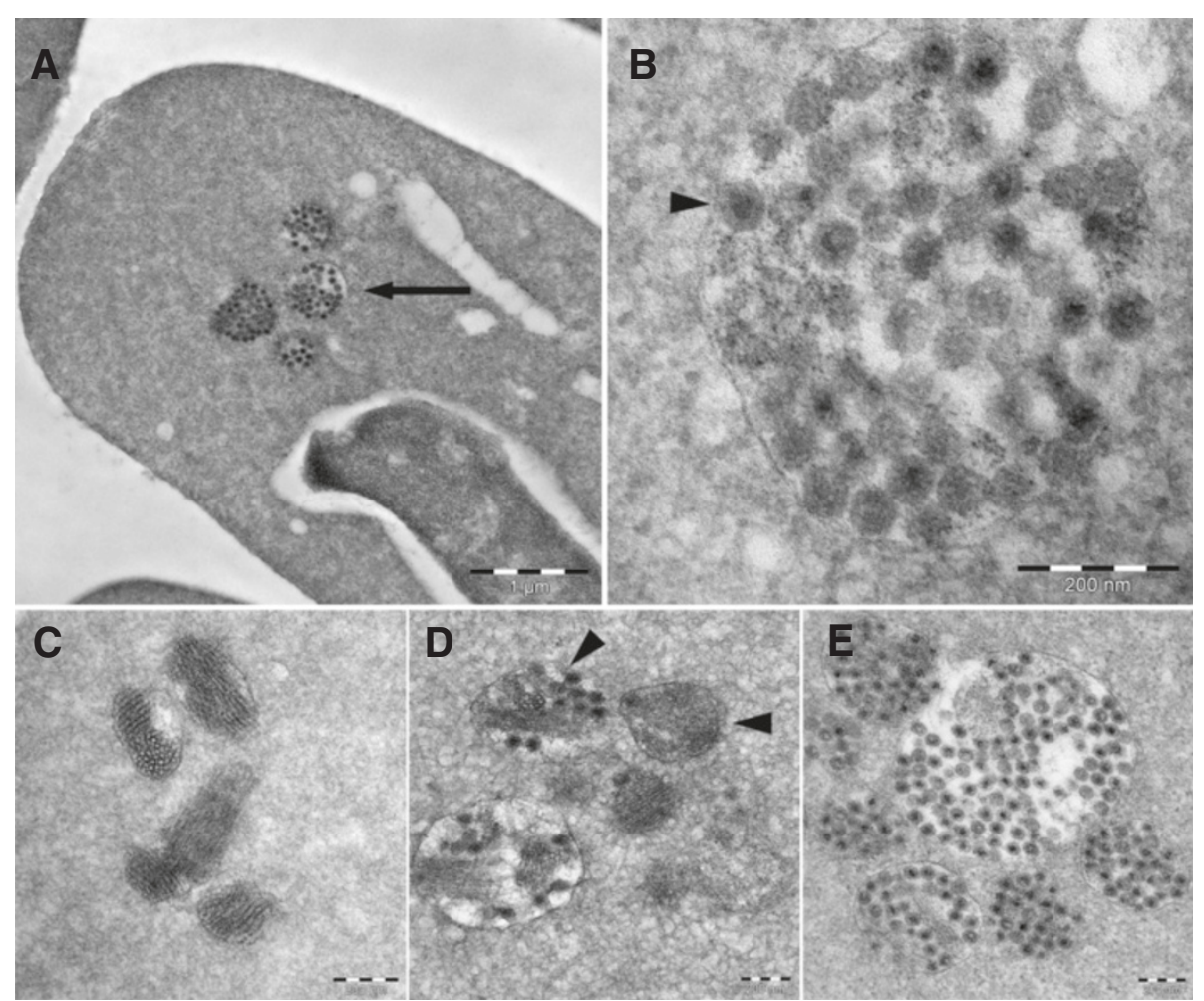

Figure 6 Transmission electron micrographs of infected RBC. A) Erythrocyte with viral inclusions (arrow). B) Inclusions containing reovirus-like particles. C) Inclusions with lamellar structure. D) Inclusions with a mixture of viral particles and lamellar structures (arrowhead). Some of the inclusions are surrounded by an intact, or partially intact membrane-like structures. E) Inclusions containing numerous reovirus-like particles.

There have been a number of reports of viral inclusions in salmonid erythrocytes that have been collectively termed EIBS [26]. No specific viruses have been recognized as causative agents and erythrocytic inclusions assumed to be of viral origin have been observed in salmonid species in both the Atlantic and Pacific, including Atlantic salmon, rainbow trout (O. mykiss), Chinook salmon (O. tshawythscha) and Coho salmon (O. kisutch) $[21,23,55]$. The PRV particles and inclusions described in our study have a striking resemblance to several of the previously reported viral inclusions described as EIBS [21-25,55]. Pinacyanol chloride staining has previously been used in identification of EIBS [26,56], and in the present study we observed stained inclusions using this techniques. These earlier reports all describe membranebound viral inclusions containing a naked virus of the same size as that of the current study and have been observed in both healthy and diseased fish, the latter with clinical signs including anemia [25,56]. A lamellar structure, as described in our study, was also noted in many of these reports $[22,24,25]$. Our findings demonstrate that erythrocytes are a major target cell for PRV in Atlantic salmon that can be observed as erythrocytic inclusions. Furthermore, it indicates that PRV is probably associated with at least some of the EIBS previously reported. However, the term EIBS comprise a number of reports from several different salmonid species. The results from the present study should prompt further investigation into the presence of PRV in EIBS infected specimens from both Atlantic and Pacific salmonid species.

Recent studies have concluded that PRV is closely related to the Orthoreovirus genus and that it encodes a protein homologous to the MRV o1 cell attachment protein $[5,6]$. MRV agglutinate erythrocytes via the o1 protein, a binding mediated by a sialic acid binding motif $[27,57]$ that is partly conserved in PRV $\sigma 1$ [6]. Given the phylogenetic relationship between MRV and PRV, it is interesting to note that virus and erythrocyte interaction is conserved. PRV could serve as an interesting model for investigating phylogenetic relationships in the family Reoviridae as it is currently the only known fish virus related to the Orthoreovirus genus.

The major function of mammalian erythrocytes is oxygen transport, and mammalian RBC undergo enucleation and loss of organelles before entering circulation [58]. This evolutionary trait benefits their oxygen-carrying capacity and has also made them more resistant to viral infections. Cold-water fish, like Atlantic salmon, have a lower oxygen 
demand and slower metabolism, and are therefore less dependent on high oxygen transport. An extreme example of low oxygen demand is Antarctic icefish (Channichthyidae) that lack both hemoglobin and erythrocytes $[59,60]$. Most non-mammalian erythrocytes, including those of fish, are nucleated and contain organelles, and can therefore potentially serve as hosts for viral replication [61]. In this study, more than $50 \%$ of the RBC of some individual fish were PRV-infected, as demonstrated by flow cytometry. As the sensitivity of the flow cytometry analysis enabled detection of infected RBC only in those individual fish with RBC RT-qPCR Ct-values of below 20, the prevalence of PRV-infected $\mathrm{RBC}$ is probably higher. Considering that $\mathrm{RBC}$ are the most abundant cells in blood, by extrapolation, total viral load in an infected fish is substantial.

Although mature erythrocytes in humans cannot support productive viral infections, Colorado tick fever virus (CTFV), a reovirus of the genus Coltivirus, has been detected in mature erythrocytes $[62,63]$. This is thought to be the result of infection of nucleated immature cells rather than of direct entry and replication of CTFV in mature erythrocytes, as CTFV has been shown to replicate in erythroblasts and reticulocytes of infected mice and in human hematopoietic progenitor cells [64,65]. Among the PRV-positive erythrocytes detected by immunofluorescence microscopy variations in cell morphology were observed, with some identified as typical ellipsoidal mature erythrocytes whereas others resembled immature erythrocytes with a more circular cellular shape [66]. In Atlantic salmon farming, factors like reduced oxygen supply and acute anemia stimulate erythropoiesis and would therefore be expected to increase the relative proportion of juvenile cells $[67,68]$. However, both young and old RBC from rainbow trout have been shown to respond to stress by altered protein production [31]. The spherical RBC observed in this study could be due to stress-induced swelling of RBC [69], and not necessarily indicate immature erythrocytes. Future studies should investigate the replicative potential for PRV in hematopoietic cells.

Several studies have been conducted in order to investigate the significance of PRV infection on the health of farmed Atlantic salmon. PRV has been shown to be the etiological cause of HSMI, as the cardiac viral load correlates with disease development and PRV antigens have been detected in cardiomyocytes, coinciding with the course of the disease $[2,18]$. However, our study shows that infection of red blood cells is an important feature of PRV infection that is not encompassed by the diagnosis of HSMI. Although HSMI is caused by PRV, the disease should probably be considered as only one possible outcome of a PRV infection. PRV infection of erythrocytes could have broader implications for fish health, irrespective of the presence of heart lesions.
Lesions in the spleen and head kidney are not included in the diagnostic criteria of HSMI. However, these blood-filled organs contain more virus compared to heart and skeletal muscle [19], which was confirmed in this study. A proportion of these high viral loads are likely due to PRV-infected RBC. In addition, both organs are immunologically important for clearance of viral infected circulating cells. Nevertheless, PRV infection in non-RBC cells in the head kidney or spleen should not be excluded. It is also worth noting that head kidney and spleen are the main hematopoietic organs in Atlantic salmon. PRV positive cells resembling leukocytes have been observed by immunohistochemistry on heart sections from HSMI diseased fish, but these cells have not been further characterized [18]. In our study it cannot be excluded that a few leukocytes could have been copurified along with RBC. However, the number would be very low compared to the massive numbers of infected RBC found in flow cytometry. Double staining using PRV antibody and specific markers for populations of Atlantic salmon leukocytes could be attempted in future studies to identify potential non-RBC target cells.

PRV is ubiquitous in healthy farmed Atlantic salmon, and occurs at lower prevalences in wild Atlantic salmon and brown trout (Salmo trutta L.) in Norway, and wild chum salmon (Oncorhynchus keta), rainbow trout (O. mykiss) and cutthrout trout (O. clarkii) in Canada $[7,10]$. The widespread occurrence of PRV in healthy farmed and wild fish could reflect infection in erythrocytes at levels that do not lead to the heart and skeletal muscle lesions seen in HSMI outbreaks. Field observations indicate that PRV is present in farmed Atlantic salmon long after cessation of an HSMI outbreak [8]. Persistent infection of erythrocytes could explain these findings, as fish erythrocytes are thought to circulate for up to 6 months [31]. It is important to note that the presence of PRV in circulating erythrocytes will influence the amount of virus detected by qPCR screening of any organ, including heart, skeletal muscle, head kidney and spleen. Residual blood containing PRV-positive cells would affect the qPCR results obtained, even if resident cells are not infected.

In conclusion, demonstration of PRV infection of erythrocytes provides new information about HSMI pathogenesis, and establishes PRV as an important factor of viral erythrocytic inclusions.

\section{Additional files}

\footnotetext{
Additional file 1: RT-qPCR Ct-values of PRV from Challenge

Experiment \# 1. RTg-PCR Ct-values of PRV in blood, heart, skeletal muscle $(S M)$, spleen and head kidney (HK) from Challenge Experiment \# 1 sampled at 0, 4, 6, 8, 10,12 and 14 weeks post challenge (wpc). Unique identifiers for the individual fish sampled are included (Ex. F101-F106). The mean Ct-value and standard deviation (Mean $( \pm$ SD)) for the different tissues are shown in the righthand column. Samples with no Ct-value
} 
were assigned the value 35.0 when used in calculation of the mean. Na: Not available.

\section{Additional file 2: RT-qPCR Ct-values of PRV from Challenge}

Experiment \# 2. RTq-PCR Ct-values of PRV in blood, RBC, spleen and plasma from Challenge Experiment \# 2 sampled at 0 and 3-8 weeks post challenge (wPc). Unique identifiers for the individual fish sampled are included (Ex. F01-F06). The mean Ct-value and standard deviation (Mean $( \pm$ SD)) for the different material are shown in the right-hand column. Samples with no Ct-value were assigned the value 35.0 when used in calculation of the mean

Additional file 3: Surface detection of PRV protein in isolated RBC from Challenge Experiment \# 2 by flowcytometry. (A) Density plot showing the gating strategy for surface staining. FS, forward scatter; SS, side scatter. (B) Negative control from 0 weeks post challenge (wpc) for surface staining representing the background fluorescence. (C) Flow cytometry results from the surface staining at 5,7 and $8 \mathrm{wpc}$. 50000 cells were counted for each sample. Individual F75 was excluded due to technical difficulties.

\section{Abbreviations}

ARV: Avian orthoreovirus; dsRNA: Double-stranded RNA; EM: Electron microscopy; ElBS: Erythrocytic inclusion body syndrome; HE: Hematoxylin-eosin; HSMI: Heart and skeletal muscle inflammation; IP: Intraperitoneally; IPNV: Infectious pancreatic necrosis virus; ISAV: Infectious salmon anemia virus; MRV: Mammalian orthoreovirus; PMCV: Piscine myocarditis virus; PBS: Phosphate-buffered saline; PRV: Piscine orthoreovirus; RBC: Red blood cells; SAV: Salmonid alfavirus; TEM: Transmission electron microscopy; VLP: Virus like particle; WPC: Weeks post challenge.

\section{Competing interests}

The authors declare that they have no competing interests.

\section{Authors' contributions}

$\varnothing W F$ participated in the overall design of the study, performed the RBC isolation, flow cytometry, immunofluorescence microscopy and electron microscopy, participated in RNA isolation and RT-qPCR, helped in interpretation of the overall data and drafted the manuscript. MKD participated in the overall design of the study, performed the RNA isolation and RT-qPCR, helped in interpretation of the overall data and drafting the manuscript. THL participated in isolation of RBC and flow cytometry, helped in interpretation of these data and revised the manuscript. IBN participated in RNA isolation and RT-qPCR, helped in the interpretation of these data and revised the manuscript. ML designed and carried out the challenge experiments and revised the manuscript. CW designed and carried out the challenge experiments and revised the manuscript. CMO carried out the confocal imaging and pinacyanol staining, helped in the interpretation of these data and revised the manuscript. AKS helped in the development the flow cytometry assay, interpretation of the data and revised the manuscript. ER participated in the overall design and coordination of the study, helped in interpretation of the overall data and drafting the manuscript. All authors read and approved the final manuscript.

\section{Acknowledgements}

The research was supported by grant \#183196/S40 of Research Council of Norway. The TEM imaging was performed at the Imaging Centre Campus Ås, Department of Plant and Environmental Sciences, Norwegian University of Life Sciences. Thanks to Trine Hvoslef-Eide, Hilde Kolstad and Elin Ørmen for technical and scientific guidance with the TEM imaging.

\section{Author details}

'Department of Food Safety and Infection Biology, Norwegian University of Life Sciences, Oslo, Norway. ${ }^{2}$ Section of Immunology, Norwegian Veterinary Institute, Oslo, Norway. ${ }^{3}$ VESO Vikan, Vikan, Namsos, Norway.

Received: 12 November 2013 Accepted: 7 March 2014

Published: 3 April 2014

\section{References}

1. Kongtorp RT, Kjerstad A, Taksdal T, Guttvik A, Falk K: Heart and skeletal muscle inflammation in Atlantic salmon, Salmo salar L.: a new infectious disease. J Fish Dis 2004, 27:351-358.

2. Palacios G, Løvoll M, Tengs T, Hornig M, Hutchison S, Hui J, Kongtorp RT, Savji N, Bussetti AV, Solovyov A, Kristoffersen AB, Celone C, Street C, Trifonov V, Hirschberg DL, Rabadan R, Egholm M, Rimstad E, Lipkin WI: Heart and skeletal muscle inflammation of farmed salmon is associated with infection with a novel reovirus. PLoS One 2010, 5:e11487.

3. Kongtorp RT, Taksdal T, Lyngøy A: Pathology of heart and skeletal muscle inflammation (HSMI) in farmed Atlantic salmon Salmo salar. Dis Aquat Organ 2004, 59:217-224.

4. Mikalsen $A B$, Haugland $\varnothing$, Rode $M$, Solbakk IT, Evensen $\varnothing$ : Atlantic salmon reovirus infection causes a CD8 T cell myocarditis in Atlantic salmon (Salmo salar L.). PLoS One 2012, 7:e37269.

5. Key T, Read J, Nibert ML, Duncan R: Piscine reovirus encodes a cytotoxic, non-fusogenic, integral membrane protein and previously unrecognized virion outer-capsid proteins. J Gen Virol 2013, 94:1039-1050.

6. Markussen T, Dahle MK, Tengs T, Løvoll M, Finstad ØW, Wiik-Nielsen CR, Grove S, Lauksund S, Robertsen B, Rimstad E: Sequence analysis of the genome of piscine orthoreovirus (PRV) associated with heart and skeletal muscle inflammation (HSMI) in Atlantic salmon (Salmo salar). PLoS One 2013, 8:e70075.

7. Kibenge MJ, Iwamoto T, Wang Y, Morton A, Godoy MG, Kibenge FS: Whole-genome analysis of piscine reovirus (PRV) shows PRV represents a new genus in family Reoviridae and its genome segment $\mathrm{S} 1$ sequences group it into two separate sub-genotypes. Virol J 2013, 10:230.

8. Løvoll M, Alarcon M, Bang JB, Taksdal T, Kristoffersen AB, Tengs T: Quantification of piscine reovirus (PRV) at different stages of Atlantic salmon Salmo salar production. Dis Aquat Organ 2012, 99:7-12.

9. Wiik-Nielsen CR, Ski P-MR, Aunsmo A, Løvoll M: Prevalence of viral RNA from piscine reovirus and piscine myocarditis virus in Atlantic salmon Salmo salar L., broodfish and progeny. J Fish Dis 2012, 35:169-171.

10. Garseth AH, Fritsvold C, Opheim M, Skjerve E, Biering E: Piscine reovirus (PRV) in wild Atlantic salmon, Salmo salar L., and sea-trout, Salmo trutto L., in Norway. J Fish Dis 2013, 36:483-493.

11. Walters MN, Joske RA, Leak PJ, Stanley NF: Murine infection with reovirus: I. Pathology of the acute phase. Br J Exp Pathol 1963, 44:427-436.

12. Attoui $H$, Mertens PPC, Becnel J, Belaganahalli S, Bergoin M, Brussaard CP, Chappell JD, Ciarlet M, del Vas M, Dermody TS, Dormitzer PR, Duncan R, Fcang Q, Graham R, Guglielmi KM, Harding RM, Hillman B, Makkay A Marzachì C, Matthijnssens J, Milne RG, Mohd Jaafar F, Mori H, Noordeloos AA, Omura T, Patton JT, Rao S, Maan M, Stoltz D, Suzuki N, et al: Reoviridae. In Virus Taxonomy: Ninth Report of the International Committee on Taxonomy of Viruses. Edited by King AMQ, Adams MJ, Carstens EB, Lefkowitz EJ. Amsterdam: Elsevier/Academic Press; 2012:541-637.

13. Ni Y, Kemp MC: A comparative study of avian reovirus pathogenicity: virus spread and replication and induction of lesions. Avian Dis 1995, 39:554-566

14. Shivaprasad HL, Franca M, Woolcock PR, Nordhausen R, Day JM, PantinJackwood M: Myocarditis associated with reovirus in turkey poults. Avian Dis 2009, 53:523-532.

15. Johansen $R$ (ed.): The health situation in norwegian aquaculture 2012 . Oslo: Norwegian Veterinary Institute; 2013

16. Ferguson HW, Kongtorp RT, Taksdal T, Graham D, Falk K: An outbreak of disease resembling heart and skeletal muscle inflammation in Scottish farmed salmon, Salmo salar L., with observations on myocardial regeneration. J Fish Dis 2005, 28:119-123.

17. Kongtorp RT, Halse M, Taksdal T, Falk K: Longitudinal study of a natural outbreak of heart and skeletal muscle inflammation in Atlantic salmon Salmo salar L. J Fish Dis 2006, 29:233-244.

18. Finstad $\varnothing W$, Falk K, Løvoll M, Evensen $\varnothing$, Rimstad E: Immunohistochemical detection of piscine reovirus (PRV) in hearts of Atlantic salmon coincide with the course of heart and skeletal muscle inflammation (HSMI). Vet Res 2012, 43:27.

19. Løvoll M, Wiik-Nielsen J, Grove S, Wiik-Nielsen CR, Kristoffersen AB, Faller R, Poppe T, Jung J, Pedamallu CS, Nederbragt AJ, Meyerson M, Rimstad E, Tengs T: A novel totivirus and piscine reovirus (PRV) in Atlantic salmon (Salmo salar) with cardiomyopathy syndrome (CMS). Virol J 2010, 7:309.

20. Kongtorp RT, Taksdal T: Studies with experimental transmission of heart and skeletal muscle inflammation in Atlantic salmon, Salmo salar L. J Fish Dis 2009, 32:253-262. 
21. Watanabe K, Karlsen M, Devold M, Isdal E, Litlabo A, Nylund A: Virus-like particles associated with heart and skeletal muscle inflammation (HSMI). Dis Aquat Organ 2006, 70:183-192.

22. Michak P, Smith CE, Hopper K: Erythrocytic inclusion body syndrome: a light and electron microscopic study of infected erythrocytes of chinook Oncorhynchus tshawytscha and coho 0. kisutch salmon. Dis Aquat Organ 1992, 12:229-233.

23. Rodger HD: Erythrocytic inclusion body syndrome virus in wild Atlantic salmon, Salmo salar L. J Fish Dis 2007, 30:411-418.

24. Graham DA, Curran W, Rowley HM, Cox DI, Cockerill D, Campbell S, Todd D: Observation of virus particles in the spleen, kidney, gills and erythrocytes of Atlantic salmon, Salmo salar L., during a disease outbreak with high mortality. J Fish Dis 2002, 25:227-234.

25. Lunder T, Thorud K, Holt RA, Rohovec JS: Particles similar to the virus of erythrocytic inclusion body syndrome, EIBS, detected in Atlantic salmon (Salmo salar) in Norway. Bull Eur Assoc Fish Pathol 1990, 10:21-23.

26. Leek SL: Viral erythrocytic inclusion body syndrome (EIBS) occurring in juvenile spring chinook salmon (Oncorhynchus tshawytscha) reared in freshwater. Can J Fish Aquat Sci 1987, 44:685-688.

27. Reiter DM, Frierson JM, Halvorson EE, Kobayashi T, Dermody TS, Stehle T: Crystal structure of reovirus attachment protein ơ1 in complex with sialylated oligosaccharides. PLOS Pathog 2011, 7:e1002166.

28. Chappell JD, Gunn VL, Wetzel JD, Baer GS, Dermody TS: Mutations in type 3 reovirus that determine binding to sialic acid are contained in the fibrous tail domain of viral attachment protein sigma1. J Virol 1997, 71:1834-1841.

29. Rosen L: Serologic grouping of reoviruses by hemagglutinationinhibition. Am J Hyg 1960, 71:242-249.

30. Dermody TS, Nibert ML, Bassel-Duby R, Fields BN: A sigma 1 region important for hemagglutination by serotype 3 reovirus strains. J Virol 1990, 64:5173-5176.

31. Lund SG, Phillips MC, Moyes CD, Tufts BL: The effects of cell ageing on protein synthesis in rainbow trout (Oncorhynchus mykiss) red blood cells. J Exp Biol 2000, 203:2219-2228.

32. Bridle A, Nosworthy E, Polinski M, Nowak B: Evidence of an antimicrobialimmunomodulatory role of Atlantic salmon cathelicidins during infection with Yersinia ruckeri. PLoS One 2011, 6:e23417.

33. Fields BN, Raine CS, Baum SG: Temperature-sensitive mutants of reovirus type 3: defects in viral maturation as studied by immunofluorescence and electron microscopy. Virology 1971, 43:569-578.

34. Rhim JS, Jordan LE, Mayor HD: Cytochemical, fluorescent-antibody and electron microscopic studies on the growth of reovirus (ECHO 10) in tissue culture. Virology 1962, 17:342-355.

35. Dales S, Gomatos PJ, Hsu KC: The uptake and development of reovirus in strain $L$ cells followed with labeled viral ribonucleic acid and ferritinantibody conjugates. Virology 1965, 25:193-211.

36. Silverstein SC, Schur PH: Immunofluorescent localization of doublestranded RNA in reovirus-infected cells. Virology 1970, 41:564-566.

37. Spendlove RS, Lennette EH, Knight CO, Chin JN: Development of vira antigen and infectious virus in HeLa cells infected with reovirus. J Immunol 1963, 90:548-553.

38. Broering TJ, Parker JS, Joyce PL, Kim J, Nibert ML: Mammalian reovirus nonstructural protein $\mu$ NS forms large inclusions and colocalizes with reovirus microtubule-associated protein $\mu 2$ in transfected cells. J Virol 2002, 76:8285-8297.

39. Parker JS, Broering TJ, Kim J, Higgins DE, Nibert ML: Reovirus core protein $\mu 2$ determines the filamentous morphology of viral inclusion bodies by interacting with and stabilizing microtubules. J Virol 2002, 76:4483-4496.

40. Arnold MM, Murray KE, Nibert ML: Formation of the factory matrix is an important, though not a sufficient function of nonstructural protein $\mu$ NS during reovirus infection. Virology 2008, 375:412-423.

41. Becker MM, Goral MI, Hazelton PR, Baer GS, Rodgers SE, Brown EG, Coombs KM, Dermody TS: Reovirus ơNS protein is required for nucleation of viral assembly complexes and formation of viral inclusions. J Virol 2001, 75:1459-1475.

42. Kobayashi T, Chappell JD, Danthi P, Dermody TS: Gene-specific inhibition of reovirus replication by RNA interference. J Virol 2006, 80:9053-9063.

43. Kobayashi T, Ooms LS, Chappell JD, Dermody TS: Identification of functional domains in reovirus replication proteins $\mu$ NS and $\mu 2$. J Virol 2009, 83:2892-2906.

44. Becker MM, Peters TR, Dermody TS: Reovirus o'NS and $\mu$ NS proteins form cytoplasmic inclusion structures in the absence of viral infection J Virol 2003, 77:5948-5963.
45. Borsa J, Copps TP, Sargent MD, Long DG, Chapman JD: New intermediate subviral particles in the in vitro uncoating of reovirus virions by chymotrypsin. J Virol 1973, 11:552-564.

46. Dryden KA, Wang G, Yeager M, Nibert ML, Coombs KM, Furlong DB, Fields BN, Baker TS: Early steps in reovirus infection are associated with dramatic changes in supramolecular structure and protein conformation: analysis of virions and subviral particles by cryoelectron microscopy and image reconstruction. J Cell Biol 1993, 122:1023-1041.

47. Metcalf $P$, Cyrklaff $M$, Adrian $M$ : The three-dimensional structure of reovirus obtained by cryo-electron microscopy. EMBO J 1991, 10:3129-3136.

48. Luftig RB, Kilham SS, Hay AJ, Zweerink HJ, Joklik WK: An ultrastructural study of virions and cores of reovirus type 3. Virology 1972, 48:170-181.

49. Mayor HD, Jamison RM, Jordan LE, Vanmitchell M: Reoviruses. II. Structure and composition of the virion. J Bacterio/ 1965, 89:1548-1556.

50. Spendlove RS, Lennette EH, Chin JN, Knight CO: Effects of antimitotic agents on intracellular reovirus antigen. Cancer Res 1964, 24:1826-1833.

51. Dales S: Association between the spindle apparatus and reovirus. Proc Natl Acad Sci U S A 1963, 50:268-275.

52. Sharpe $A H$, Chen $L B$, Fields BN: The interaction of mammalian reoviruses with the cytoskeleton of monkey kidney CV-1 cells. Virology 1982, 120:399-411.

53. Mayor HD: Studies on reovirus. III. A labile, single-stranded ribonucleic acid associated with the late stages of infection. J Natl Cancer Inst 1965, 35:919-925.

54. Gomatos PJ, Tamm I, Dales S, Franklin RM: Reovirus type 3: physical characteristics and interaction with L cells. Virology 1962, 17:441-454.

55. Meyers TR: First report of erythrocytic inclusion body syndrome (EIBS) in chinook salmon Oncorhynchus tshawytscha in Alaska, USA. Dis Aquat Organ 2007, 76:169-172

56. Piacentini SC, Rohovec JS, Fryer JL: Epizootiology of erythrocytic inclusion body syndrome. J Aquat Anim Health 1989, 1:173-179.

57. Chappell JD, Duong JL, Wright BW, Dermody TS: Identification of carbohydrate-binding domains in the attachment proteins of type 1 and type 3 reoviruses. J Virol 2000, 74:8472-8479.

58. Parmley RT: Mammals. In Vertebrate Blood Cells. Edited by Rowley HM, Ratcliffe NA. Cambridge: Cambridge University Press; 1988:337-424.

59. Brett JR: The metabolic demand for oxygen in fish, particularly salmonids, and a comparison with other vertebrates. Respir Physiol 1972 14:161-170

60. Garofalo F, Pellegrino D, Amelio D, Tota B: The Antarctic hemoglobinless icefish, fifty five years later: a unique cardiocirculatory interplay of disaptation and phenotypic plasticity. Comp Biochem Physiol A Mol Integr Physiol 2009, 154:10-28.

61. Claver JA, Quaglia AIE: Comparative morphology, development, and function of blood cells in nonmammalian vertebrates. J Exot Pet Med 2009, 18:87-97.

62. Emmons RW, Oshiro LS, Johnson HN, Lennette EH: Intra-erythrocytic location of Colorado tick fever virus. J Gen Virol 1972, 17:185-195.

63. Hughes LE, Casper EA, Clifford CM: Persistence of Colorado tick fever virus in red blood cells. Am J Trop Med Hyg 1974, 23:530-532.

64. Philipp CS, Callaway C, Chu MC, Huang GH, Monath TP, Trent D, Evatt BL: Replication of Colorado tick fever virus within human hematopoietic progenitor cells. J Virol 1993, 67:2389-2395.

65. Oshiro LS, Dondero DV, Emmons RW, Lennette EH: The development of Colorado tick fever virus within cells of the haemopoietic system. J Gen Virol 1978, 39:73-79.

66. Conroy DA: Basic Atlas of Atlantic Salmon (Salmo Salar L.) Blood Cells Carrickfergus: Patterson Peddie Consulting Ltd; 2006.

67. Lewis JM, Klein G, Walsh PJ, Currie S: Rainbow trout (Oncorhynchus mykiss) shift the age composition of circulating red blood cells towards a younger cohort when exposed to thermal stress. J Comp Physiol B 2012, 182:663-671.

68. Krasnov A, Timmerhaus G, Afanasyev S, Takle H, Jørgensen SM: Induced erythropoiesis during acute anemia in Atlantic salmon: a transcriptomic survey. Gen Comp Endocrinol 2013, 192:181-190.

69. Sørensen B, Weber R: Effects of oxygenation and the stress hormones adrenaline and cortisol on the viscosity of blood from the trout Oncorhynchus mykiss. J Exp Biol 1995, 198:953-959.

doi:10.1186/1297-9716-45-35

Cite this article as: Finstad et al.: Piscine orthoreovirus (PRV) infects Atlantic salmon erythrocytes. Veterinary Research 2014 45:35. 